University of Nebraska - Lincoln

DigitalCommons@University of Nebraska - Lincoln

\title{
Genetic Measures Confirm Familial Relationships and Strengthen Study Design
}

\author{
Stacie J. Robinson \\ University of Wisconsin \\ Ryan D. Walrath \\ University of Wisconsin \\ Timonthy R. VanDeelen \\ University of Wisconsin \\ Kurt C. VerCauteren \\ USDA-APHIS-Wildlife Services, kurt.c.vercauteren@usda.gov
}

Follow this and additional works at: https://digitalcommons.unl.edu/icwdm_usdanwrc

Part of the Life Sciences Commons

Robinson, Stacie J.; Walrath, Ryan D.; VanDeelen, Timonthy R.; and VerCauteren, Kurt C., "Genetic Measures Confirm Familial Relationships and Strengthen Study Design" (2012). USDA Wildlife Services Staff Publications. 1550.

https://digitalcommons.unl.edu/icwdm_usdanwrc/1550

This Article is brought to you for free and open access by the U.S. Department of Agriculture: Animal and Plant Health Inspection Service at DigitalCommons@University of Nebraska - Lincoln. It has been accepted for inclusion in USDA Wildlife Services - Staff Publications by an authorized administrator of DigitalCommons@University of Nebraska - Lincoln. 


\title{
Genetic Measures Confirm Familial Relationships and Strengthen Study Design
}

\author{
STACIE J. ROBINSON, ${ }^{1}$ Department of Forest and Wildlife Ecology, University of Wisconsin, 1630 Linden Drive, Room 208 Russell Labs, \\ Madison, WI 53706, USA \\ RYAN D. WALRATH, Department of Forest and Wildlife Ecology, University of Wisconsin, 1630 Linden Drive, Room 208 Russell Labs, Madison, \\ WI 53706, USA \\ TIMOTHY R. VANDEELEN, Department of Forest and Wildlife Ecology, University of Wisconsin, 1630 Linden Drive, Room 208 Russell Labs, \\ Madison, WI 53706, USA \\ KURT C. VerCAUTEREN, National Wildife Research Center, United States Department of Agriculture, Animal and Plant Health Inspection \\ Service, Wildlife Services, 4101 LaPorte Avenue, Fort Collins, CO 80521, USA
}

\begin{abstract}
Social structure and behavioral interactions between individuals shape basic biological processes, such as breeding; foraging and predator avoidance; movement and dispersal; and disease transmission. We used a targeted trapping strategy to capture kin groups of white-tailed deer (Odocoileus virginianus) during 2007 and 2008 in Sandhill Wildlife Research Area, Wisconsin, USA, in order to observe social behaviors. Because inferring family relationships from observation of behavior is subjective, we used measures of genetic relatedness and parentage assignment tests to determine that our capture strategy was efficient for capturing related pairs ( $78 \%$ of groups contained $\geq 1$ dyad of related animals). The results of our genetic tests verified that study animals were related; therefore, our capture strategy was successful and the assumptions of the research design were met. This demonstrates both the utility of a targeted sampling approach, and the importance of genetic techniques to verify relationships among animals, especially when kin association forms a basis for further biological study or management action. Published 2012. This article is a U.S. Government work and is in the public domain in the USA.
\end{abstract}

KEY WORDS capture, epidemiology, genetics, Odocoileus virginianus, relatedness, trapping, white-tailed deer.

Family and social groups form the basic building blocks of wildlife population structure. Social interactions between individuals can affect basic biological processes, such as breeding; foraging and predator avoidance; movement and dispersal; and disease transmission. Transmissible diseases, such as chronic wasting disease (CWD) and bovine tuberculosis $(\mathrm{TB})$, present growing challenges in the management of white-tailed deer (Odocoileus virginianus). Managers and epidemiologists increasingly are interested in the role that social structure might play in transmitting such diseases.

Deer typically associate in small social groups wherein related female deer are the basic unit of social structure in white-tailed populations (Hirth 1977, Marchinton and Hirth 1984). Social group structure has many important implications from biology to management. Social interactions play a key role in shaping dispersal patterns of white-tailed deer, which can affect demographic and micro-evolutionary processes (Nelson 1993, Long et al. 2008). This micro-scale group structure shapes the genetic structure of deer populations, both locally (Scribner et al. 1997, Comer et al. 2005, Blanchong et al. 2006) and regionally (Leberg and Ellsworth 1999, Robinson et al. 2012).

Received: 2 December 2010; Accepted: 31 March 2012

Published: 18 June 2012

${ }^{1}$ E-mail: sjrobinson@wisc.edu
Successful management actions also depend on understanding social group structure within a population (e.g., managing population levels and expansion [Porter et al. 1991] or mitigating human-wildlife conflicts [Festa-Bianchet and Apollonio 2003]). In the face of emerging wildlife diseases, social behavior is also particularly important in terms of interactions or contacts that could transfer disease. Contact rates are typically elevated among animals in social groups, which creates avenues for disease transmission and establishment (Altizer et al. 2003). Rates of direct and indirect contact between individual deer has been correlated with joint space use, and contact is especially high among members of the same social group (Schauber et al. 2007). These elevated rates of interaction suggest that social structure in female deer could facilitate spread of diseases (Anderson and May 1979, Schauber et al. 2007). Field studies have supported this principle, demonstrating higher infection within family groups for both bovine $\mathrm{TB}$ (Blanchong et al. 2007) and CWD (Grear et al. 2010).

Given the biological and management importance, there is strong motivation to study social group structure and social behavior of deer. However, it can be challenging to conduct field studies of kin behavior because family relationships cannot be discerned visually. Family groups have been identified by joint space use or inferred based on co-capture of animals, or by sighting animals that are together (Aycrigg and 
Porter 1997, Miller et al. 2010). Yet relatedness by proximity may not always be a valid assumption (Rosenberry et al. 2009). Calculating relatedness based on genetic data can validate whether individuals traveling together are related (Queller and Goodnight 1989). Recently, Rosenberry et al. (2009) used genetic analysis and found that a surprisingly low proportion of adult-fawn capture-groups were related, which suggests that caution is warranted in interpreting co-capture as an indication of kin group membership.

We offer a different perspective and suggest that, depending on research goals, scientists could conduct capture sessions to effectively target closely related kin groups of deer. For behavioral observation research, we attempted to capture closely related groups of deer (Walrath et al. 2011). We designed our capture strategy to maximize the chances of effectively capturing animals belonging to discrete family groups, which differed from the attempt to maximize size of groups captured that was employed by Rosenberry et al. (2009). We applied genetic techniques similar to those used in previous research to assess the effectiveness of our targeted sampling approach.

\section{STUDY AREA}

Our study took place at Sandhill Wildlife Research Area (SWRA), located near Babcock, Wisconsin, USA. The SWRA was a $37-\mathrm{km}^{2}$ research facility that was maintained by the Wisconsin Department of Natural Resources and was surrounded by a $2.7-\mathrm{m}$ high, deer-proof fence. The property was composed of flat, marshy land interspersed with oak (Quercus spp.), aspen (Populus spp.), and jack-pine (Pinus banksiana) forests.

\section{METHODS}

We captured deer from February to April in 2007 and 2008 using rocket-propelled nets (Kilpatrick et al. 1997, Cromwell et al. 1999, Haulton et al. 2001) or drop-nets (White and Bartmann 1994, Peterson et al. 2003, Jedrzejewski and Kamler 2004) at sites baited with corn, alfalfa pellets, molasses, and apples. We followed a targeted capture strategy to preferentially obtain related pairs. Our strategy depended on use of behavioral cues to identify maternal pairs ( $F$ and offspring from the previous birth pulse). Deer were captured when a group of 2-3 animals with $\geq 1$ fawn approached the bait pile together without showing signs of aggression (e.g., striking, ears back, charging, etc.). We inferred age (fawn or ad) from relative size and conformation. In order to capture multiple groups without interrelatedness among groups, trapping areas were set up at the northern and southern ends of SWRA so that each trapping area would likely cover nonoverlapping home ranges of unrelated (U) animals ( $\geq 3.2-\mathrm{km}$ apart; Larson et al. 1978). Deer capture and handling included anesthetization with xylazine $\mathrm{HCl}$ (2.5 mg/kg; IVX Animal Health, Inc., St. Joseph, MO) and Telozol 1 (1:1 tiletamine hydrochloride and zolazepam hydrochloride association; $3.5-5.0 \mathrm{mg} / \mathrm{kg}$; Fort Dodge Animal Health, Fort Dodge, IA) and reversal with xylazine with Tolazoline $\mathrm{HCl}$ (3 mg/kg; Akorn, Inc., Decatur, IL), tissue collection, collaring, and marking for additional studies (Walrath et al. 2011). All handling protocols were approved by the University of Wisconsin-Madison Institutional Animal Care and Use Committee (protocol no. A1272).

We collected tissues from ear-punch samples from each deer, and stored samples frozen at $-20^{\circ} \mathrm{C}$ until DNA extraction. We extracted whole genomic DNA from earpunch tissues using the Qiagen DNeasy extraction kit (Qiagen Inc., Valencia, CA) by following manufacturer's protocol to use half of each ear punch in each reaction. We genotyped deer at 9 highly variable microsatellite loci (Anderson et al. 2002, DeYoung et al. 2003) chosen for their high levels of polymorphism in the Wisconsin deer population (Blanchong et al. 2008, Grear et al. 2010). We amplified loci using the Qiagen multiplex Polymerase Chain Reaction kit, following the manufacturer's protocol (Qiagen Inc.). Mix 1 included loci BM1225, BM4107, BM6506, N, and RT23, and was run with a $54^{\circ} \mathrm{C}$ annealing temperature. Mix 2 included loci BM4208, BM6438, OarFCB193, and RT27, and was run with a $57.5^{\circ} \mathrm{C}$ annealing temperature. Each reaction was run for 30 cycles. Polymerase chain reaction products were visualized using an ABI3130 (Applied Biosystems Inc., Life Technologies Corp., Carlsbad, CA), and genotypes were determined using GeneMarker 1.7 software (SoftGenetics LLC, State College, PA). We verified all genotypes in 2 independent amplifications (1 genotype had to be rerun for verification after a mismatch between the 2 replicates at 1 allele; no other genotyping error was detected). We used probability of identity statistics $\left(P_{\mathrm{ID}}\right.$ and $P_{\mathrm{IDsibs}}$, performed in GenAlEx; Peakall and Smouse 2006) to ensure that we had adequate power to identify closely related individuals in our dataset.

We then used a 2-step approach to examine the relatedness among pairs. We first tested whether female-fawn pairs could be described as mother and offspring and then looked at the proportion of relatedness between all possible pairs of animals to examine more distant relationships. We used Program CERVUS (Marshall et al. 1998) to identify parent-offspring pairs. We used the maternity analysis model for which the input includes a list of potential offspring (for which we included all fawns) and a list of potential mothers (for which we included all adult F). To better characterize background allele frequencies, we also included a set of 100 individuals randomly chosen from a larger dataset from a collaborating study covering the same area of south-central Wisconsin (Robinson et al. 2012). The program compared each fawn's genotype with each mother's genotype and assigned each offspring to a most likely mother (based on the highest log-likelihood ratio). Confidence in parentage assignment was calculated based on simulations in CERVUS (we simulated 1,000 offspring, 500 mothers, a 0.5 sampling rate, and an allowance of $1 \%$ missing data). We set a relaxed confidence level of $80 \%$, so that if no mother could be assigned with $\geq 80 \%$ certainty, then no mother would be assigned to that fawn. We examined whether each cocaptured pair represented a mother and offspring, and whether any of the females captured mothered any fawns other than those with whom they were captured. 
We measured genetic relatedness to quantify the identical fraction of 2 genomes (DeWoody 2005). Genomic relatedness $\left(r_{x y}\right)$ represents the proportion of allelic composition shared between individuals $x$ and $y$ (Queller and Goodnight 1989). Researchers assume that this quantity represents identity by descent - that individuals share genetic information through co-ancestry as opposed to arriving at the same sets of alleles through spontaneous mutations (Queller and Goodnight 1989). The $r_{x y}$ statistic ranges from 0 to 1 , with 0 reflecting individuals sharing none of their genetic makeup and 1 indicating identical pairs (e.g., clonally reproduced organisms or identical twins in sexually reproducing organisms; Lynch and Ritland 1999). Theory suggests first-order relatives such as full-siblings or parent-offspring pairs should share half their genetic makeup (i.e., $r_{x y}=0.5$ ). Halfsiblings or grandparent-grandchild pairs, termed secondorder relatives, would be expected to share only a quarter of their ancestry (i.e., $r_{x y}=0.25$ ). Results for $r_{x y}$ in empirical studies may vary substantially from theoretical values based on the variability of markers used and the genetic diversity of the population under study. For all pairs of deer, we calculated the relatedness coefficient $r_{x y}$ and determined the most likely pedigree relationship between individuals using a maximum likelihood approach implemented in Program MLRELATE (Kalinowski et al. 2006). We were thus able to determine whether animals captured together were related in any way other than mother-offspring pairs (e.g., other firstorder relatives such as full-siblings, or second-order relatives such half-siblings, or unrelated).

\section{RESULTS}

Eight adult females and 13 fawns were captured in 9 groups; 6 pairs, 1 group of 3, 1 group of 4, with an average group size of 2.3. Of the 9 groups, 1 was a fawn pair, and the others contained $\geq 1$ adult female and 1 fawn. The microsatellite panel provided quality data for parentage analysis, with little missing data, numerous alleles, high heterozygosity, and adherence to Hardy-Weinberg equilibrium (note that only locus $\mathrm{N}$ exhibited heterozygote deficiency and significant deviation from Hardy-Weinberg equilibrium, but this may be expected due to the small sample size, and no deviations or null alleles have been noted in larger samples of this region; Robinson et al. 2012; Table 1). Our 9-locus dataset gave us a $P_{\mathrm{ID}}$ of $8.0 \mathrm{e}-13$ and $P_{\mathrm{IDsibs}}$ of $7.8 \mathrm{e}-5$, which indicated fine resolution of genetic differences be- tween individuals (i.e., probability of identity gives the probability that individuals will have identical genotypes by chance, or that sibs will have identical genotypes by chance). Our probabilities were extremely low, which suggests that the probability of our pairs appearing related by chance were almost zero.

Overall, the probability of capturing related pairs with small trapping groups was high; we found that 7 of 11 (64\%) possible female-fawn pairs were actually motheroffspring pairs. Of 9 captured groups, 7 (78\%) contained $\geq 1$ set of related animals, either mother-offspring pairs or second-order relatives (Table 2). We identified 7 motheroffspring pairs through parentage assignment in CERVUS. All but one of the female-fawn pairs captured together represented a mother-offspring pair; the other (group E) was related at the second-order (half-sibling) level, possibly representing a female that had adopted a related fawn, or half-sibling from different years that were captured without their mother. Group $\mathrm{H}$ contained a mother with 2 offspring as well as an additional unrelated fawn. Group $\mathrm{G}$ contained an adult female with 2 unrelated fawns. The pair of fawns captured together (group I) was not assigned to mothers from any other capture group, nor were they related to each other. We note that, for 2 of these pairs, ML-RELATE assigned a lower level of relationship (groups D and F were both called full-siblings rather than parent-offspring pairs). However, $r_{x y}$ values were very near 0.5 , and both parentoffspring or full-siblings are considered first-order relatives, so this can be attributed to differences in assignment algorithms and/or difficulty distinguishing close relationship classes.

The pair-wise relatedness values further indicated that captured pairs were related (Table 2). The average relatedness between mother-offspring pairs was $r_{x y}=0.445$. The female-fawn-fawn group $\mathrm{G}$ had low $r_{x y}$ values between all pairings $(\bar{x}=0.088)$, which indicated that not even a distant relationship existed between these animals. The fawn-fawn pair captured together in group I was unrelated $\left(r_{x y}=0.036\right)$, and the third fawn captured with group $\mathrm{H}$ was not related to the adult female or to either of the other fawns $\left(\bar{x} r_{x y}=0.000\right)$. There was one instance in which individuals were first-order relatives (fawn siblings) captured at different times, and 4 cases in which second-order individuals (half-siblings or cousins) were captured at different times. In general, there was little

Table 1. Genetic data based on 9 microsatellites genotyped in white-tailed deer captured in Sandhill Wildlife Research Area near Babcock, Wisconsin, USA, 2007-2008. For each locus, we show the number of animals missing data, the number of alleles detected, expected and observed heterozygosity, and their ratio (HEexp, HEobs, HEobs:exp, respectively) and the $P$-values from an exact test for deviation from Hardy-Weinberg equilibrium (HWE).

\begin{tabular}{|c|c|c|c|c|c|c|}
\hline Locus & Missing data & No. alleles & HEexp & HEobs & HE obs:exp & HWE \\
\hline BM 6506 & 1 & 11 & 19.884 & 20 & 1.006 & 0.903 \\
\hline BM 1225 & 0 & 5 & 15.267 & 16 & 1.048 & 0.049 \\
\hline $\mathrm{N}$ & 0 & 13 & 20.022 & 12 & 0.599 & 0.000 \\
\hline RT233 & 1 & 10 & 18.791 & 19 & 1.011 & 0.938 \\
\hline BM 4107 & 0 & 9 & 19.244 & 21 & 1.091 & 0.835 \\
\hline OarFCB1093 & 0 & 9 & 19.467 & 19 & 0.976 & 0.201 \\
\hline RT27 & 0 & 12 & 18.844 & 16 & 0.849 & 0.103 \\
\hline BM 6438 & 0 & 11 & 19.711 & 20 & 1.015 & 0.730 \\
\hline BM4208 & 0 & 12 & 20.556 & 22 & 1.070 & 0.671 \\
\hline
\end{tabular}


Table 2. Parentage assignments and pair-wise genetic relationships between groups of white-tailed deer captured in Sandhill Wildlife Research Area near Babcock, Wisconsin, USA, 2007-2008. We provide the relationship assigned to each individual in Program CERVUS and to each pair in Program MLRELATE ( $\mathrm{PO}=$ parent-offspring, FS = full-siblings, $\mathrm{HS}=$ half-siblings, $\mathrm{U}=$ unrelated). As a measure of confidence in the relationship classification, we provide the change in log-likelihood value from the relationship shown versus an assignment of $\mathrm{U}(\Delta \mathrm{LnL}$ to $\mathrm{U})$. The $r_{x y}$ shows genetic relatedness between pairs.

\begin{tabular}{|c|c|c|c|c|}
\hline Capture group & Age & $\begin{array}{l}\text { Parentage assignment } \\
\text { CERVUS }\end{array}$ & $\begin{array}{l}\text { Most likely relationship } \\
\text { ML-relate ( } \Delta \operatorname{LnL} \text { to } U)\end{array}$ & $\begin{array}{c}\text { Pair-wise } r_{x y} \\
\text { ML-relate }\end{array}$ \\
\hline \multirow[t]{2}{*}{ A } & Adult & Mother & PO (10.99) & 0.500 \\
\hline & Fawn & Offspring & & \\
\hline \multirow[t]{2}{*}{ B } & Adult & Mother & PO (6.83) & 0.524 \\
\hline & Fawn & Offspring & & \\
\hline \multirow[t]{2}{*}{$\mathrm{C}$} & Adult & Mother & PO (4.66) & 0.500 \\
\hline & Fawn & Offspring & & \\
\hline \multirow[t]{2}{*}{$\mathrm{D}$} & Adult & Mother & FS (3.84) & 0.399 \\
\hline & Fawn & Offspring & & \\
\hline \multirow[t]{2}{*}{$\mathrm{E}$} & Adult & None & HS (0.66) & 0.270 \\
\hline & Fawn & None & & \\
\hline \multirow[t]{2}{*}{$\mathrm{F}$} & Adult & Mother & FS (3.66) & 0.450 \\
\hline & Fawn & Offspring & & \\
\hline \multirow[t]{3}{*}{ G } & Adult & None & $\mathrm{U}(0.00)$ & $\bar{x}=0.088$ \\
\hline & Fawn & None & & \\
\hline & Fawn & None & & \\
\hline \multirow[t]{5}{*}{$\mathrm{H}$} & Adult & Mother & & \\
\hline & Fawn & Offspring & PO (5.71) & to mom 0.500 \\
\hline & Fawn & Offspring & PO (5.53) & to mom 0.500 \\
\hline & & & HS (2.72) & sibs 0.378 \\
\hline & Fawn & None & $\mathrm{U}(0.00)$ & $\bar{x}=0.000$ \\
\hline \multirow[t]{2}{*}{ I } & Fawn & $\mathrm{n} / \mathrm{a}$ & $\mathrm{U}(0.00)$ & $\bar{x}=0.036$ \\
\hline & Fawn & $\mathrm{n} / \mathrm{a}$ & & \\
\hline
\end{tabular}

relatedness between capture groups $\left(\max r_{x y}=0.222\right.$, $\bar{x}=0.054$; Table 3 ), which suggests that capture times and locations were adequately spaced to avoid capture of overlapping kin groups between sessions.

\section{DISCUSSION}

Genetic relationship analysis proved a valuable tool in validating assumptions of relatedness for the study of behavior as a function of kin group. Our analysis also helped demonstrate that, with a targeted capture strategy, researchers have a high probability of obtaining the desired related pairs.

Our results differed markedly from some previous studies. Our success in capturing related animals can be attributed to the specific group-targeting strategy employed in our capture methodology, selecting animals of mixed-age groups traveling together that showed nonaggressive behavior. For example, other researchers have found lower average relatedness within social groups when sampling only adult groups (Grear et al. 2010, Miller et al. 2010); our inclusion of fawns improved our chances of sampling closely related pairs. One similar study found common capture to be a poor predictor of familial relationships even when considering adults and fawns (Rosenberry et al. 2009). The capture season, snow conditions, and palatable bait source were very similar between studies. Both their study population and ours were hunted, though without specific data on the harvest intensity we cannot strictly rule out different disruptions of kin in the social structure in each study area. The major difference between studies is, evidently, selectivity of capture. Rosenberry et al. (2009) captured a diverse set of groups with deer numbers ranging from 2 to 7 , averaging 3.7 deer/group. Our capture effort specifically focused on smaller groups and used behavioral cues to make trapping decisions, and our average capture group was just over half the size of the previous study. Further, candidate groups had to approach the bait pile together and show no aggressive behaviors. This level of specificity likely enabled us to reliably capture related pairs.

Table 3. Average genetic relatedness between white-tailed deer caught in different capture groups in Sandhill Wildlife Research Area near Babcock, Wisconsin, USA, 2007-2008. The diagonal (shaded gray) shows the average relatedness within each capture group. The off-diagonal shows average relatedness of all pairings between capture groups ( $r_{x y}$ values from ML-RELATE).

\begin{tabular}{lcccccccc}
\hline Group & A & B & C & D & E & F & G & H \\
\hline A & 0.500 & & & & & & \\
B & 0.000 & 0.524 & & & & & \\
C & 0.027 & 0.004 & 0.500 & & & & \\
D & 0.023 & 0.048 & 0.041 & 0.420 & & & \\
E & 0.151 & 0.038 & 0.065 & 0.073 & 0.327 & & \\
F & 0.000 & 0.197 & 0.112 & 0.085 & 0.019 & 0.492 & & \\
G & 0.059 & 0.035 & 0.075 & 0.012 & 0.033 & 0.014 & 0.088 & \\
H & 0.029 & 0.035 & 0.065 & 0.072 & 0.143 & 0.051 & 0.025 & 0.234 \\
I & 0.030 & 0.078 & 0.007 & 0.222 & 0.000 & 0.101 & 0.042 & 0.033 \\
\hline
\end{tabular}




\section{MANAGEMENT IMPLICATIONS}

Genetic analysis continues to grow more efficient and costeffective and is playing an increasingly important role in ecological studies. Our assessment of genetic relatedness was critical in verifying assumptions about social structure for behavioral observation research. Genetic tests enable researchers to overcome the subjectivity of having to assume kin relationships in behavior studies. Genetic research provides a valuable tool for epidemiological research and is applicable to a diversity of other research questions.

Our research suggests that targeting small groups of closely associated deer can reliably obtain related groups (78\% of the time in this study). However, it is not safe to assume that cocapture absolutely indicates close relationship. We note that some of our capture groups were unrelated, and other studies have found much lower likelihood of capturing related groups (Rosenberry et al. 2009). This demonstrates both the utility of a targeted sampling approach, and the importance of genetic techniques to verify relationships among animals, especially when kin association forms a basis for biological study or management action.

\section{ACKNOWLEDGMENTS}

Primary funding for this research was provided by the U.S. Department of Agriculture-Animal and Plant Health Inspection Services-Wildlife Services-National Wildlife Research Center, Fort Collins, Colorado, USA. We thank the Wisconsin Department of Natural Resources and Wisconsin Department of Natural Resources Bureau of Integrated Science Services for additional support and access to our research site. We thank the University of Wisconsin Madison Department of Forest and Wildlife Ecology for help with publication costs. Finally, we deeply thank M. Watt, W. Hall, and all technicians, volunteers, and staff who assisted on this project. Publication of this manuscript does not constitute endorsement or censure of any of the products mentioned by the authors or their employers.

\section{LITERATURE CITED}

Altizer, S., C. L. Nunn, P. H. Thrall, J. L. Gittleman, J. Antonovics, A. A. Cunningham, A. P. Dobson, V. Ezenwa, K. E. Jones, A. B. Pedersen, M. Poss, and J. R. C. Pulliam. 2003. Social organization and parasite risk in mammals: integrating theory and empirical studies. Annual Review of Ecology Evolution and Systematics 34:517-547.

Anderson, J. D., R. L. Honeycutt, R. A. Gonzales, K. L. Gee, L. C. Skow, Z. L. Gallagher, D. A. Honeycutt, and R. W. DeYoung. 2002. Development of microsatellite DNA markers for the automated genetic characterization of white-tailed deer populations. Journal of Wildlife Management 66:67-74.

Anderson, R. M., and R. M. May. 1979. Population biology of infectious diseases: Part I. Nature 280:361-367.

Aycrigg, J. L., and W. F. Porter. 1997. Sociospatial dynamics of white-tailed deer in the central Adirondack Mountains, New York. Journal of Mammalogy 78:468-482.

Blanchong, J. A., M. D. Samuel, K. T. Scribner, B. V. Weckworth, J. A. Langenberg, and K. B. Filcek. 2008. Landscape genetics and the spatial distribution of chronic wasting disease. Biology Letters 4:130-133.

Blanchong, J. A., K. T. Scribner, B. K. Epperson, and S. R. Winterstein. 2006. Changes in artificial feeding regulations impact white-tailed deer fine-scale spatial genetic structure. Journal of Wildlife Management 70:1037-1043.
Blanchong, J. A., K. T. Scribner, A. N. Kravchenko, and S. R. Winterstein. 2007. TB-infected deer are more closely related than non-infected deer. Biology Letters 3:103-105.

Comer, C. E., J. C. Kilgo, G. J. D’Angelo, T. C. Glenn, and K. V. Miller. 2005. Fine-scale genetic structure and social organization in female whitetailed deer. Journal of Wildlife Management 69:332-344.

Cromwell, J. A., R. J. Warren, and D. W. Henderson. 1999. Live-capture and small-scale relocation of urban deer on Hilton Head Island, South Carolina. Wildlife Society Bulletin 27:1025-1031.

DeWoody, J. A. 2005. Molecular approaches to the study of parentage, relatedness, and fitness: practical applications for wild animals. Journal of Wildlife Management 69:1400-1418.

DeYoung, R. W., S. Demarais, R. L. Honeycutt, R. A. Gonzales, K. L. Gee, and J. D. Anderson. 2003. Evaluation of a DNA microsatellite panel useful for genetic exclusion studies in white-tailed deer. Wildlife Society Bulletin 31:220-232.

Festa-Bianchet, M., and M. Apollonio. 2003. Animal behavior and wildlife conservation. Island Press, Washington, D.C., USA.

Grear, D. A., M. D. Samuel, K. T. Scribner, B. V. Weckworth, and J. A. Langenberg. 2010. Influence of genetic relatedness and spatial proximity on chronic wasting disease infection among female white-tailed deer. Journal of Applied Ecology 47:532-540.

Haulton, S. M., W. F. Porter, and B. A. Rudolph. 2001. Evaluating 4 methods to capture white-tailed deer. Wildlife Society Bulletin 29:255-264.

Hirth, D. H. 1977. Social behavior of white-tailed deer in relation to habitat. Wildlife Monographs 53.

Jedrzejewski, W., and J. F. Kamler. 2004. Modified drop-net for capturing ungulates. Wildlife Society Bulletin 32:1305-1308.

Kalinowski, S. T., M. L. Taper, and T. C. Marshall. 2006. Revising how the computer program CERVUS accommodates genotyping error increases success in paternity assignment. Molecular Ecology 16:1099-1106.

Kilpatrick, H. J., S. M. Spohr, and A. J. DeNicola. 1997. Darting urban deer: techniques and technology. Wildlife Society Bulletin 25:542-546.

Larson, T. J., O. J. Rongstad, and F. W. Terbilcox. 1978. Movement and habitat use of white-tailed deer in southcentral Wisconsin. Journal of Wildlife Management 42:113-117.

Leberg, P. L., and D. L. Ellsworth. 1999. Further evaluation of the genetic consequences of translocations on southeastern white-tailed deer populations. Journal of Wildlife Management 63:327-334.

Long, E. S., D. R. Diefenbach, C. S. Rosenberry, and B. D. Wallingford. 2008. Multiple proximate and ultimate causes of natal dispersal in whitetailed deer. Behavioral Ecology 19:1235-1242.

Lynch, M., and K. Ritland. 1999. Estimation of pairwise relatedness with molecular markers. Genetics 152:1753-1766.

Marchinton, R. L., and D. H. Hirth. 1984. Behavior. Page 129-168 in L. K. Halls, editor. White-tailed deer ecology and management. Stackpole, Harrisburg, Pennsylvania, USA.

Marshall, T., J. Slate, L. Kruuk, and J. Pemberton. 1998. Statistical confidence for likelihood-based paternity inference in natural populations. Molecular Ecology 7:639-655.

Miller, B. F., R. W. DeYoung, T. A. Campbell, B. R. Laseter, W. M. Ford, and K. V. Miller. 2010. Fine-scale genetic and social structuring in a central Appalachian white-tailed deer herd. Journal of Mammalogy 91:681-689.

Nelson, M. E. 1993. Natal dispersal and gene flow in white-tailed deer in northeastern Minnesota. Journal of Mammalogy 74:316-322.

Peakall, R., and P. E. Smouse. 2006. GenAlEx 6: genetic analysis in Excel. Population genetic software for teaching and research. Molecular Ecology Notes 6:288-295.

Peterson, M. N., R. R. Lopez, P. A. Frank, M. J. Peterson, and N. J. Silvy. 2003. Evaluating capture methods for urban white-tailed deer. Wildlife Society Bulletin 31:1176-1187.

Porter, W. F., N. E. Mathews, H. B. Underwood, R. W. J. Sage, and A. B. Donald. 1991. Social organization in deer: implications for localized management. Environmental Management 15:809-814.

Queller, D. C., and K. F. Goodnight. 1989. Estimating relatedness using genetics markers. Evolution 43:258-275.

Robinson, S. J., M. D. Samuel, D. Lopez, P. Shelton. 2012. The walk is never random: anthropogenic landscape barriers shape subtle population structure in a Midwestern white-tailed deer population. Molecular Ecology DOI: 10.1111/j.1365-294X.2012.05681.x.

Rosenberry, C., E. Long, H. Hassel-Finnegan, V. Buonaccorsi, D. Diefenbach, and B. Wallingford. 2009. Lack of mother-offspring 
relationships in white-tailed deer capture groups. Journal of Wildlife Management 73:357-361.

Schauber, E. M., D. J. Storm, and C. K. Nielsen. 2007. Effects of joint space use and group membership on contact rates among white-tailed deer. Journal of Wildlife Management 71:155-163.

Scribner, K. T., M. H. Smith, and R. K. Chesser. 1997. Spatial and temporal variability of microgeographic genetic structure in white-tailed deer. Journal of Mammalogy 78:744-755.
Walrath, R., T. R. Van Deelen, and K. C. VerCauteren. 2011. Efficacy of proximity loggers for detection of contacts between maternal pairs of white-tailed deer. Wildlife Society Bulletin 35:452-460.

White, G. C., and R. M. Bartmann. 1994. Drop nets versus helicopter net guns for capturing mule deer fawns. Wildlife Society Bulletin 22:248-252.

Associate Editor: Rominger. 